\title{
EL SENADO Y LA CONFERENCIA DE PRESIDENTES ${ }^{1}$
}

\author{
FERNANDO REVIRIEGO PICÓN \\ Profesor Ayudante de Derecho Constitucional \\ Universidad Nacional de Educación a Distancia
}

Como en un juego de palabras Senado y reforma son dos vocablos que se vienen ligando indefectiblemente y hasta la saciedad desde la propia aprobación de nuestro texto constitucional, que pese a haber caracterizado a aquél como cámara de representación territorial no habilitó en el resto de sus disposiciones que dicha definición pudiera tener efectividad práctica. No parece preciso abundar con especial detalle en esta idea ni hacer una reseña de las críticas que ya desde ese mismo momento encontramos en la doctrina ${ }^{2}$. El Senado, aunque habría que introducir ciertos matices, no sería en líneas generales sino una cámara de segunda lectura y retardo, de influencia limitada, en donde acostumbra a reproducirse el equilibrio de fuerzas de la cámara baja; ello con una posición que ha permitido hablar de un "bicameralismo irrelevante" (singularmente visible cuando esa equivalencia no se produce), por más que en ocasiones pueda habilitar con su actuación ciertas distorsiones del funcionamiento normal de las instituciones ${ }^{3}$.

La conciencia de esta necesidad de reforma se ha sentido con claridad no sólo en la doctrina — donde ya es un lugar común la asociación antes apuntada-, sino también en el ámbito político, al ser contemplado por muchos como elemento imprescindible para la consolidación definitiva de ese modelo

1 Una versión de estas notas se presentó como comunicación al IV Congreso de la Asociación de Constitucionalistas de España, celebrado en Baeza el 17 y 18 de noviembre de 2005.

2 Sin ánimo exhaustivo, cabe recordar como R. PUNSET lo vino en calificar tempranamente como una Cámara anodina, llena de contradicciones, carente de personalidad concreta y sumido a fuerza de mestizajes en la indefinición más absoluta, "El Senado en la nueva Constitución española", Revista de la Facultad de Derecho de la Universidad Complutense, n. ${ }^{0}$ 57, 1979, págs. 137 y ss.

3 E. ALBERTÍ se sirve de la expresión de LIJPHART (Democracies: Patterns of Majoritarian and Consensos Government in Twenty One Countries, Yale, New Haven, 1984) tras apuntar la incapacidad del Senado para cumplir con su función de representación territorial y al no desempeñar un papel de límite o contrapeso dentro del sistema de gobierno, por más que apunta a continuación que su "mayor docilidad" ante el Gobierno hace surgir en ocasiones la tentación de hurtar determinadas cuestiones al proceso de deliberación pública, "La representación territorial", Fundamentos (La representación política), n. 3, 2004, pág. 45.

UNED. Teoria y Realidad Constitucional, núm. 17, 2006, pp. 355-369. 
territorial que dibujara de forma un tanto indefinida nuestro constituyente. Respecto de aquélla nos remitimos al extenso repertorio bibliográfico que se contiene en este mismo número; respecto de ésta a lo reflejado en los diferentes programas de los partidos que concurrieron a las últimas elecciones generales. Las dudas y discrepancias existentes estribarían únicamente en el modo de llevar a cabo dicha reforma; especialmente su alcance y contenido definitivo en la concreción de su vocación representativa. Aunque, en todo caso, no debe dejarse de lado el aparente marco de desinterés hacia la misma por parte de las instituciones más próximas a aquella ${ }^{4}$.

Las propuestas de reforma han sido en consecuencia muchas aunque su plasmación práctica de escasa efectividad y claramente insuficiente. Hasta la fecha, derivado en parte de la existencia de un cierto "miedo" a la reforma constitucional - lato senso considerada-, el intento de acomodación de la actuación de la Cámara a su caracterización constitucional, acentuando su dimensión territorial, habría venido por la vía reglamentaria exclusivamentes.

Cabría recordar aquí, por ejemplo, aunque sin entrar a abordar sus competencias -informativas, consultivas-, la creación de la Comisión General de las Comunidades Autónomas en 1994 (reforma de escasa efectividad), cuya convocatoria, no olvidemos, puede ser solicitada por cualquiera de los Consejos de Gobierno de las Comunidades Autónomas 6 . La última de las reformas reglamentarias, que entró en vigor en septiembre de 2005, ha permitido el uso de las lenguas cooficiales en la totalidad de las sesiones de la referida Comisión, autorizando igualmente la publicación, en el Boletín de la Cámara, de las mociones, interpelaciones o preguntas que, junto a la versión en castellano, pudieran presentarse en alguna de aquellas lenguas.

Dicho lo anterior, lo cierto es que en la presente Legislatura la reforma de este órgano parece haber entrado en otra fase que quizá pueda terminar por sacarla de esa suerte de vía muerta en la que se encontraba; aunque quizá nuevamente nos encontramos ante otro espejismo.

4 Como apuntaron recientemente E. AJA y C. VIVER «la principal rémora para la reforma se encuentra en la falta de empuje de las instituciones más próximas al propio Senado, porque nadie tiene interés a corto plazo en cambiar un Senado dócil e inoperante por otro fuerte y exigente, "Valoración de 25 años de autonomía", Revista Española de Derecho Constitucional, n. ${ }^{\circ} 69$, 2003, pág. 108.

5 F. J. GUTIÉRREZ, tras señalar que el debate político en los primeros momentos no pudo ir más allá de la discusión sobre la forma en la que habrían de agruparse los Senadores, destaca que no se supo aprovechar convenientemente la elaboración del Reglamento de 1982 para tratar de volcar la actividad de la segunda cámara del lado de la territorialidad, El debate sobre la reforma del Senado, Senado, Madrid, 2004, pág. 473.

6 Sobre esta reforma E. AJA ha destacado que "la presencia ordinaria de los Presidentes y Consejeros autonómicos en esta Comisión del Senado y su facultad para participar en la organización del orden del día, sin ser miembros de la Cámara, llegan al límite de las posibilidades del reglamento parlamentario. Seguramente por eso, tras esta reforma reglamentaria tan ambiciosa se entró en la dinámica de la reforma constitucional", "La reforma constitucional del Senado para convertirlo en una Cámara autonómica", La reforma constitucional del Senado, AJA, E., ALBERTÍ, E., RUÍZ, J.J., CEPC, Madrid, 2005, pág. 13. 
Esta cuestión se recogió (hubiera resultado llamativo que no lo fuera) en los cuatro puntos que el Gobierno de la Nación elevó a consulta al Consejo de Estado respecto de la tan cacareada reforma del texto constitucional; recordemos, aunque sólo a efectos enumerativos, los otros puntos (de muy diverso calado) sobre los que se habría solicitado consulta; así, el orden de sucesión en la Corona y la recepción en la Constitución del proceso de construcción europeo y la denominación oficial de las Comunidades Autónomas.

Más concretamente lo hizo con relación a las siguientes cuestiones: funciones que debe ejercer el Senado como cámara de representación territorial, composición más adecuada para ejercer esas funciones, posición institucional en el seno de las Cortes Generales y consecuencias sistemáticas que comportaría en el conjunto de la estructura constitucional la adopción del correspondiente modelo de configuración del Senado.

Si bien no ha sido el primer momento en que la reforma constitucional en este punto se ha podido poner sobre el tapete de una manera aparentemente seria (recordemos por ejemplo la Ponencia de estudio constituida en el seno de la Comisión Conjunta de las Comisiones General de las Comunidades Autónomas y Constitucional allá por la V Legislatura), lo cierto es que la situación política parece ahora sustancialmente diferente. Cuestión oscurecida en todo caso dentro del marco de este generalizado proceso de reforma estatutaria que se ha abierto, y que centra, de manera un tanto obsesiva, la vida política en los últimos tiempos ${ }^{7}$.

La reforma no es nada sencilla evidentemente. En primera instancia resultaría preciso clarificar el horizonte al que se quiere llegar, la concreta estrategia, cuestión sobre la que se producirán las primeras discrepancias. Sólo aclarado este punto podrán hacerse las propuestas oportunas respecto de dos cuestiones necesariamente ligadas, esto es, tanto la extracción de los miembros de dicha Cámara, como su ámbito competencial. Modelos en los que fijarse no faltarían precisamente siendo de muy diverso tenor; ahí estaría por ejemplo uno de los citados habitualmente por nuestra doctrina al abordar estas cuestiones (bien para posicionarse a favor del mismo, bien en contra), el Senado tipo Consejo, al estilo del Bundesrat alemán.

Las presentes notas no irían encaminadas tanto a entrar en ese específico debate que, sin duda, será desarrollado con habilidad e ingenio por alguno de los otros trabajos de este monográfico, como a plantear la proyección y relieve político que, dentro de este genérico marco de discusión, pudiera recabar un foro de negociación e interlocución como la Conferencia de Presidentes autonómicos, tanto en su versión vertical (articulada recientemente) como horizontal (inédita hasta la fecha pese a sus indudables potencialidades).

Foro que, como es sabido, acaba de celebrar — repitamos, con una dimensión exclusivamente vertical— su segunda reunión, teniendo como prin-

7 Sobre el más polémico de estos procesos recomendamos vivamente la lectura del artículo de F. DE CARRERAS publicado en el n. ${ }^{\circ} 16$ de Teoria y Realidad Constitucional ( Reflexiones sobre la propuesta de nuevo Estatuto de Cataluña"). 
cipal tema de discusión la articulación de un nuevo sistema de financiación de la Sanidad en orden a sustituir el aprobado en la anterior Legislatura. Un foro pertinente, al decir de Bocanegra Sierra y Huergo Lora al ser "cauce apropiado para el reconocimiento de la importancia política que en todo caso les corresponde a las Comunidades Autónomas y para solucionar los bloqueos institucionales que pueden producirse en el funcionamiento de un Estado compuesto, pero también, como igualmente se ha apuntado, esa instancia es necesaria para permitir la cooperación entre las Comunidades Autónomas y la defensa de sus intereses comunes" ${ }^{8}$.

Ligar este espacio de encuentro, negociación y acuerdo, la Conferencia de Presidentes autonómicos, al debate sobre la reforma del Senado es, a nuestro parecer, de indudable interés; no en vano, si este foro se llega a gestionar de manera inteligente, puede llegar a convertirse en un adecuado y necesario complemento de dicha Cámara en lo que a la participación de las Comunidades Autónomas haría referencia y en orden a la consecución de un funcionamiento eficaz y equilibrado del sistema en su conjunto, ayudando a aquilatar tensiones territoriales. No habría que perder de vista tampoco el hecho, no sólo anecdótico, de que el Senado haya sido el lugar elegido para la celebración de sus sesiones?.

Ahora bien, estamos hablando claramente de lo que sería a nuestro modo de ver un importante complemento para esa función de interacción e integración territorial que debe cumplir la Cámara Alta, mas en ningún caso sirviendo de reemplazo de ésta en ese objeto; o cuando menos no debiera llegar a serlo..

No obstante lo anterior, lo cierto es que la experiencia comparada nos muestra supuestos en donde el teórico complemento a una Cámara con similar finalidad y caracterización se ha terminado por convertir en una suerte de sustituto.

Como así lo ha apuntado García Morales, la no consecución de auténticas cámaras de representación territorial en los estados federales ha llevado a la articulación alternativa de procedimientos participados, provocando que las instancias federadas hagan valer sus intereses a través de órganos de colaboración fuera del ámbito parlamentario; órganos que en la práctica llegarían a ser más importantes que la propia segunda Cámara ${ }^{10}$. De ahí que puede entenderse el recelo que en determinados países ha suscitado en la Cámara Alta la creación de un órgano de las características del que ahora nos ocupa ${ }^{11}$.

8 La Conferencia de Presidente, Iustel, Madrid, 2005, pág. 63.

9 Si bien tras la primera reunión el Presidente del Gobierno barajó la itinerancia de la Conferencia (Barcelona era la sede apuntada en primera instancia para la celebración de su segunda sesión) finalmente se estableció el Senado como su sede definitiva y permanente.

10 "Tendencias actuales de la colaboración en los federalismos europeos: una perspectiva comparada"; Cuadernos de Derecho Público, n. ${ }^{2}$ 2, 1997, pág. 244; véase, también, AJA, E., El Estado autonómico Federalismo y hechos diferenciales, Alianza Editorial, Madrid, 1999, págs. 198 y ss.

$11 \mathrm{Al}$ abordar la experiencia de la Conferencia de Gobiernos cantonales creada en Suiza en 1993, M. J. GARCÍA MORALES, reseña este dato si bien apunta inmediatamente a continuación el intento de mantenimiento en la actualidad, de relaciones basadas en la comunicación y en la colaboración, "La Conferencia de Gobiernos cantonales en Suiza", "La Conferencia de Gobiernos Cantonales en Suiza: regulación y balance de funcionamiento", Revista Vasca de Administración Pública, n. ${ }^{\circ} 72,2005$, pág. 38 y ss. 
Ejemplo de esa sustitución lo ofrecería por ejemplo la Conferencia de Presidentes de los Länder en Austria, una suerte de "poder en la sombra" (Macht im Schatten $)^{12}$ frente a un devaluado Bundesrat ${ }^{13}$, que entre otras actuaciones, elaboraría los programas de peticiones de los Länder, papel de trabajo previo a las reformas de la Constitución federal, y negociaría los proyectos de leyes sobre compensación financiera entre Bund y Länder ${ }^{14}$.

Más allá de este dato y volviendo a nuestra realidad concreta, es preciso apuntar que si bien parece difícil extraer conclusiones de la actuación de un órgano cuando apenas lleva el bagaje de dos reuniones escasas (si se me apura, una sola derivada de que la primera no fue sino — permítasenos el símil— una especie de bal des débutantes), lo cierto es que en este escaso tiempo hemos podido ver sus potencialidades.

Aunque quizá con más claridad, habríamos podido comprobar también los peligros a qué se enfrenta, esencialmente su eventual subordinación a estrategias puramente partidistas, pero también los que derivarían del formato elegido para su desarrollo, a nuestro parecer escasamente perfilado, que no cabría achacar a la invención de un foro novedoso, puesto que más allá de los referentes comparados, ya contaríamos con propuestas concretas de articulación desde mucho tiempo atrás. Recordemos por ejemplo la detallada propuesta presentada con ocasión de la constitución en el Senado de la Comisión General de las Comunidades Autónomas, al hilo del primer debate sobre la situación del Estado de las Autonomías. En aquella ocasión se propuso, en orden a su eventual institucionalización jurídica, lo siguiente: "Texto legal que se propone: I. Se crea la Conferencia de Presidentes formada por los Presidentes de los Consejos de Gobierno de las Comunidades Autónomas, además del Presidente del Gobierno que la presidirá, actuando de Secretario el Ministro de la Presidencia. Los miembros podrán asistir acompañados del personal que estimen conveniente. II. La Conferencia tendrá carácter deliberante tomando sus acuerdos por unanimidad, reuniéndose semestralmente o a petición de un tercio de sus miembros en la sede que se fije para la reunión. III. La Conferencia debatirá cuestiones generales de interés común, que no corresponden a órganos creados por Ley para esta finalidad, y coordinará las Conferencias Sectoriales. IV. La Conferencia emitirá su parecer sobre los proyectos normativos de la Unión Europea y designará a los representantes autonómicos en las Comisiones Interadministrativas para los Asuntos Económicos relacionados con la Unión Europea y de seguimiento y coordinación de las actuaciones relacionadas con la defensa del Estado español ante el Tribunal de Justicia de las Comunidades (UE)». A ello se añadía que "Su creación se hará por ley,

12 PERNTHALER, P., "La Conferencia de Presidentes de los Länder en la evolución del federalismo cooperativo en Austria", Seminario sobre la Conferencia de Presidentes, IDP, Barcelona, 2004; sobre la representatividad de esta cámara y la creación de foros alternativos para cuestiones específicas ("Conferencia de los Länder para la Integración"), véase también, ALBERTÍ, E., "El Bundesrat austríaco", Ante el futuro del Senado, Institut d’Estudis Autonòmics, Barcelona, 1996, págs. 150/151.

13 VERNET I LLOBET, J., El sistema federal austríaco, Marcial Pons, Madrid, 1997, pág. 108

14 GARCÍA MORALES, M.J., "Tendencias actuales de la colaboración en los federalismos europeos: una perspectiva comparada", cit., pág. 244. 
dejando los detalles concretos de su estructura a un Reglamento elaborado por la propia Conferencia ${ }^{15}$. En todo caso, ni que decir tiene que las expectativas abiertas por esta Comisión, por el propio Debate sobre el Estado de las Autonomías (del que no haría falta recordar su evolución), incluso por esta Conferencia, se irían remitiendo rápidamente, relegando, por lo que a esta última cuestión haría referencia, la propuesta al olvido ${ }^{16}$.

Dicho esto veamos ahora brevemente el desarrollo práctico de este foro.

La primera de las Conferencias, con los lógicos interrogantes y dudas que toda novedad suscita, se celebró en octubre de 2004, precedida de diferentes reuniones preparatorias coordinadas desde el Ministerio de Administraciones Públicas; ello, sin ausencia alguna. Su exclusiva articulación vertical llevó a Bocanegra y Huergo a apuntar, de manera un tanto crítica, que "en España se ha comenzado primando lo accesorio (al menos desde la perspectiva del modelo alemán) sobre lo principal, pues la Conferencia ha nacido por iniciativa del Presidente del Gobierno mientras que en Alemania se sostiene sobre la iniciativa de los Presidentes de los Länder sin perjuicio de que éstos celebren también reuniones con el Canciller federal ${ }^{17}$. Más allá de esta cuestión, entrando en los temas tratados en aquella reunión, hay que referir que fueron esencialmente tres: la institucionalización de la Conferencia, las relaciones de las autonomías con la Unión Europea y el déficit sanitario. Sobre la primera de las cuestiones la duda esencial (más allá de cuestiones sobre la ubicación, itinerante o no, de la Conferencia) fue la determinación del número de reuniones que habría de tener en última instancia este órgano, entendiéndose necesario en todo caso la celebración de una reunión anual, aunque abriéndose la posibilidad a una segunda. El valor de las reuniones, resultaba evidente, se reducía a la consecución de declaraciones políticas, alcanzadas por consenso, en los principales temas de la vida política ${ }^{18}$. La segunda de las cuestiones alcanzó escaso acuerdo apun-

15 El principio de cooperación: Conferencia de Presidentes, Debate sobre la situación del Estado de las Autonomías. Comisión General de las Comunidades Autónomas del Senado, 26 de septiembre de 1994, págs. 31/32.

16 Véase, AJA, E., "El Senado", La experiencia constitucional (1978/2000), TRUJILLO, G., LÓPEZ GUERRA, L., GONZÁlEZ-TREVIJANO, P., CEPC, Madrid, 2000, págs. 380 a 383.

17 La Conferencia de Presidentes, cit., pág. 48. E. AJA, por su parte, tras señalar que la historia de nuestro sistema autonómico apenas ha contemplado la colaboración horizontal refiere que "la Conferencia vertical o mixta es el objetivo a conseguir de manera inmediata, pero en la confianza de que su desarrollo significará a corto o medio plazo el de una Conferencia horizontal simultánea en la que progresivamente se ampliará también el tratamiento de las cuestiones de carácter horizontal", Informe sobre la Conferencia de Presidentes.

18 MONTILLA MARTOS, en un estudio sobre relaciones intergubernamentales, nos habla de este foro como "nivel simbólico político" del marco institucional de colaboración-participación; el "nivel de decisión política ordinaria" correspondería aquí a un Senado reformado, y el "nivel técnico" a las Conferencias Sectoriales, "Apuntes sobre colaboración y participación en el Estado autonómico. A propósito de la propuesta de reforma del Estatuto de Cataluña", Revista d'Estudios Autonómics $i$ Federals, n. ${ }^{\circ}$ 1, 2005, págs. 131 y ss. Una interesante relación de funciones a desempeñar por esta Conferencia podemos encontrarla en CÁMARA VILLAR, G., "La Conferencia de Presidentes como instrumento de integración para el Estado autonómico: problemas y perspectivas", El Estado autonómico. Integración, solidaridad y diversidad, Vol. I, Colex-INAP, Madrid, 2005, págs. 127/128. 
tándose la necesidad de elaborar propuestas en este sentido en orden a alcanzar una posición común. Más fructífera resultaría la última cuestión al acordarse la constitución de grupos de trabajo para el análisis del gasto sanitario que habilitarían la elaboración de una propuesta del Gobierno para dotar de suficiencia y sostenibilidad futura al sistema sanitario.

La experiencia de esta primera Conferencia pareció ser positiva, mostrando claramente su potencialidad, especialmente a la vista del dato de que el debate político subsiguiente pasó a contemplarse desde su prisma; toda cuestión parecía susceptible de ser residenciada en la misma, y así lo trataban de hacer los diferentes actores. Como apuntamos en otra ocasión al abordar este foro, en los últimos meses pasamos de apenas haber oído hablar de la Conferencia de Presidentes, fuera de sede doctrinal, se entiende, a no poder abrir un periódico o escuchar una declaración política sin encontrar una referencia a la misma. Este foro (el entusiasmo se atemperaría con posterioridad) parecía haberse convertido por arte de magia en una suerte de bálsamo de fierabrás que todo lo cura; cualquier cuestión parecía que debía debatirse en ella para poder ser validada. En todo caso la confirmación de esas expectativas abiertas habría de comprobarse evidentemente en las siguientes conferencias.

Inmediatamente después de la celebración de la primera Conferencia se anunció (con un contenido mucho más amplio que el finalmente articulado) que la segunda acontecería bien en primavera, bien a principios del verano de 2005 .

Diferentes motivos comenzaron a postergar dicha reunión, si bien podría apuntarse que uno de los motivos fundamentales, añadiríamos que el más determinante, no fue otro que la celebración de elecciones en Galicia y el cambio de gobierno que podría en su caso producirse - como así finalmente aconteció-, hecho que determinaría un importante cambio del panorama político autonómico $^{19}$. De esta manera, a finales de junio del año en curso se remitió desde presidencia de gobierno una carta a todos los Presidentes autonómicos anunciando la celebración de la Conferencia en los primeros días de septiembre, concretándose con posterioridad la fecha del 6 de septiembre por más que en última instancia, mediante nueva misiva, se postergaría al día 10. En el contenido de las mismas se reseñaba que el objeto de la convocatoria era "la revisión del sistema de financiación sanitaria y la adopción de las decisiones que procedan para enjugar el déficit que en distintas comunidades se haya podido producir como consecuencia de la aplicación efectiva del sistema de financiación acordado hace unos años", añadiéndose como objetivo "dotar de estabilidad al conjunto del sistema, mediante la asunción de compromisos compartidos por el Gobierno de la nación y por los distintos Gobiernos de las Comunidades Autónomas".

19 Conocidos los resultados de las elecciones (PP, 37, PSG, 25, BNG, 13), y ante el anunciado pacto de gobierno PSOE-BNG, se barajó la celebración de la Conferencia los últimos días de julio, aunque la posibilidad de que la formación del gobierno se dilatara y hubiera de acudir a la misma el entonces Presidente de la Xunta en funciones, desechó dicha posibilidad. La toma de posesión se realizó finalmente el 2 de agosto. 
Conforme la fecha se acercaba, y conocida a grandes rasgos la propuesta del Gobierno, los temores a una división entre comunidades en función de criterios partidistas comenzaron a crecer. Se esperaba una postura unívoca en aquellas Comunidades Autónomas en las que el Partido Popular se encontraba en el Gobierno. Lo que a comienzos de verano parecía anticiparse como una reunión tranquila al no haber en el horizonte próximo elección alguna, parecía enrarecerse conforme la fecha inicialmente prevista se acercaba. En todo caso y antes de dar tiempo a escenificarse una división de tal carácter, algunas de las Comunidades Autónomas con gobiernos socialistas se desmarcaron igualmente de una propuesta que implicara la subida de ciertos impuestos, hecho que terminó provocando en última instancia que el Gobierno introdujera importantes cambios en la propuesta inicial.

Carece de sentido entrar ahora a diseccionar en detalle el contenido de la propuesta ya que evidentemente la cuestión menor (para lo que a nosotros interesa) serían los elementos técnicos del debate, siendo lo realmente esencial la forma de hacerlo, esto es el foro elegido y su específico desarrollo. La cuestión se planteó en primera instancia en la reunión del Consejo de Política Fiscal y Financiera de 7 de septiembre, llegándose a presentar una propuesta alternativa por parte de las Comunidades Autónomas del Partido Popular ${ }^{20}$. La división no fue finalmente la que parecía anticiparse días antes y terminó con el convencimiento de que la Conferencia de Presidentes, a la que el Gobierno llevaría una propuesta modificada, podría terminar por sacar la situación del estancamiento en que se encontraba.

Esta Conferencia, criticada duramente por su organización y formato, y que parecía ofrecer ad extra una cierta sensación de improvisación, terminaría finalmente con declaraciones políticas completamente contradictorias pese a la afirmación de una suerte de "consenso básico" por parte del Gobierno en torno al tema objeto de debate, la financiación de la Sanidad ${ }^{21}$.

La propuesta realizada en su seno venía a suponer la entrega por parte del Gobierno, sin exigencia de contraprestación alguna, de una importante cuantía en orden a la financiación de la sanidad ${ }^{22}$; a ello habría que añadir la posibilidad de que estas, autónomamente, incrementaran algunos impuestos (electricidad, matriculación o carburantes ${ }^{23}$ ). Esta propuesta sería ratificada en la pos-

20 A la par que se planteaba este debate, desde Izquierda Unida se planteó la necesidad de crear una Comisión Mixta Congreso-Senado para mejorar el Sistema Nacional de Salud.

21 Una de las principales críticas al desarrollo de la Conferencia vino provocada no solo por su escasa duración sino por la forma de ofrecer documentación e informes por parte del Gobierno, no en vano durante su celebración se llegaron a ofrecer a la prensa datos de la propuesta (o, mejor, de la contrapropuesta) que todavía no se habían expuesto en el seno de la Conferencia misma.

22 Es destacable el incremento en un 170\% de la propuesta inicialmente apuntada por el Gobierno diez días antes de la celebración de la Conferencia; implicaría una aportación directa por parte del Estado de unos 1700 millones y anticipos a cuenta de alrededor de 1400.

23 Según cálculos realizados el aprovechamiento de dichos incrementos podría suponer un montante global de 1800 millones de euros. 
terior reunión del Consejo de Política Fiscal y Financiera celebrada tres días después, aunque con la abstención de las Comunidades Autónomas del Partido Popular al apuntarse por estas la indefinición del reparto definitivo ${ }^{24}$.

La primera plasmación de este acuerdo sería la aprobación del Decreto Ley $12 / 2005$, de 16 de septiembre, por el que se aprobaron determinadas medidas urgentes en materia de financiación sanitaria, procediéndose a la autorización de anticipos de tesorería y a la subida de determinados impuestos especiales; así, bebidas alcohólicas y tabaco. La justificación de la asociación de la subida de estos impuestos a la financiación sanitaria se hizo apuntando la presunta coherencia de la finalidad perseguida al incidir sobre productos cuyo consumo puede ser nocivo para la salud y en consecuencia generadores de gasto sani$\operatorname{tario}^{25}$.

Hecho este pequeño bosquejo de las dos reuniones, debemos afirmar que la celebración de la segunda Conferencia nos ha dejado un cierto sabor agridulce. Por un lado parece consolidarse la idea de la necesidad de un foro de estas características que se reúna de manera periódica (también de su dimensión exclusivamente horizontal que complementaría la cooperación en otros niveles), pero por otro da la impresión de que en última instancia puede llegar a operar como una mera escenificación de relaciones de poder en función de bloques políticos o como mero elemento propagandístico. Evitar ambos peligros es complejo.

Como hemos venido apuntando, las deficiencias del Senado y las dificultades de su reforma en orden a hacer efectiva su caracterización como cámara de representación territorial, ha acentuado y potenciado la aparición en escena de un foro como la Conferencia de Presidentes que pretendería impulsar y reforzar el principio de colaboración. Principio que tendría unas ventajas que a todos se nos hacen evidentes, puesto que, en sentido genérico consideradas, y en palabras de García Morales, son un medio para evitar procesos de centralización y, a la par, instrumento de participación e integración de las instancias territoriales en decisiones generales ${ }^{26}$. Colaboración entendida como deber que no sería preciso justificarlo en preceptos concretos al ser "de esencia" a dicho modelo, como así lo ha señalado el Tribunal Constitucional en reiteradas sentencias desde la ya lejana STC 18/1982, de 4 de mayo. A ello podríamos añadir las reflexiones de Albertí, cuando (sin dejar de apuntar los riesgos de la

24 En medios políticos se sugirió que esta abstención pudo venir provocada por la oposición de alguna de estas CCAA a votar en contra de la propuesta (concretamente, Baleares y CastillaLeón) y al intento de consecución de una votación unánime en el seno del Consejo.

25 En la exposición de motivos del Decreto Ley se apuntó que ese “incremento de fiscalidad produce el doble efecto de proporcionar fondos que financien el gasto sanitario, a la vez que el propio gasto se reduce en la medida en que el consumo de dichos productos se desincentivan.

26 Como problemas de la colaboración apuntará la complejidad de los procesos de decisión y la eventual marginación de los parlamentos, "La cooperación en los federalismos europeos: significado de la experiencia comparada para el Estado autonómico", Revista de Estudios Autonómi$\cos$, n. ${ }^{\circ} 1,2002$, págs. 115 y ss. De esta misma autora, "Tendencias actuales de la colaboración en los federalismos europeos: una perspectiva comparada", Cuadernos de Derecho Público, n. ${ }^{\circ}$ 2, 1997. 
"desparlamentarización" del sistema político ${ }^{27}$ ) refiere que la legitimación del modelo autonómico tiende a plantearse cada vez más conforme términos utilitaristas de eficacia, para cuyo objetivo las relaciones de colaboración serían su instrumento básico; así, el funcionamiento y futuro del mismo dependería de un adecuado diseño de las relaciones de colaboración entre todos los entes entre los que se distribuye el poder estatal ${ }^{28}$.Y en un sentido más concreto, como apuntaría Aja aplicado al foro que aquí nos ocupa, la funcionalidad de la Conferencia sería triple: impulsar la participación de las Comunidades Autónomas en las decisiones centrales, el desarrollo de la coordinación horizontal y vertical (y así la garantía frente a las intervenciones estatales y una mejor gestión de las actuaciones autonómicas) y la canalización institucional de los conflictos políticos interterritoriales ${ }^{29}$.

Dicho esto, parecería preciso vincular ahora, cuando menos brevemente, la hipótesis de la reforma del Senado con este tipo de foro que pretende ser elemento determinante dentro de los instrumentos de cooperación; tanto en su dimensión vertical como horizontal —caso de crearse este último-30. Esto es, una vez instituido este foro, plantearse cual sería su vigencia (no su desarrollo actual, que no debe verse condicionado por un futurible) "frente" o "junto a" un Senado reformado, que, llegado el caso, serviría también como espacio de concertación y cooperación de las Comunidades Autónomas entre sí y con el Estado ${ }^{31}$.

27 Se sirve el autor de esta expresión de KISHER (Kooperation im Bundesstaat, Mohr Siebeck, Tübingen, 1971) tras apuntar que la capacidad de decisión de los procesos cooperativos tiende a desplazarse a los Ejecutivos, "que se encuentran en condiciones mucho mejores para desarrollar complejas y largas negociaciones que los Parlamentos, de modo que éstos se ven relegados en muchas ocasiones a desempeñar un papel de meras máquinas de ratificación de los acuerdos logrados en sede ejecutiva", "La colaboración entre el Estado y las Comunidades Autónomas", El futuro de las autonomias. Balance y perspectivas, MARTíN REBOLLO, L., (Dir.), Universidad de Cantabria, Santander, 1991, pág. 209.

28 "La colaboración entre el Estado y las Comunidades Autónomas", cit., pág. 217.

29 Informe sobre la Conferencia de Presidentes (resultado del Seminario celebrado en Barcelona en julio de 2004).

30 Si bien no parece presumible a corto plazo la articulación horizontal de esta Conferencia, lo cierto es que sería una instancia de enorme utilidad, como así lo demuestra la experiencia comparada. La apuesta por el bilateralismo por parte de algunas Comunidades que entienden que pueden encontrar así mayores réditos, sería una de las razones de su difícil creación; véase, SOLOZABAL ECHAVARRÍA, J. J., Nación y Constitución. Soberanía y autonomía en la forma política española, Biblioteca Nueva, Madrid, 2004, págs. 337/338. Es interesante apuntar al hilo de esta idea que, recientemente, con ocasión de la polémica suscitada por el proyecto de reforma del Estatuto de Cataluña, el Presidente de la Generalitat invitó al resto de Presidentes autonómicos a que se celebrara una reunión conjunta de todos ellos en donde poder explicar su modelo estatutario. Ello a la par (aunque aquí en una perspectiva vertical) que se solicitaba al Presidente del Gobierno, por parte de los Presidentes autonómicos y regionales del PP, la convocatoria de una tercera Conferencia con el objeto de estudiar dicho proyecto y sus consecuencias.

31 En la primera de las cuestiones planteadas por el Gobierno al Consejo de Estado con relación a la reforma constitucional del Senado se encontraba pronunciarse sobre este punto así como sobre las funciones que debe ejercer el Senado como cámara de representación territorial y, en particular, el ámbito material y el grado de participación en el ejercicio de la potestad legislativa y las atribuciones relacionadas con otros órganos constitucionales. 
Ahora bien, ¿̇de qué Senado estaríamos hablando? No pretendemos aquí abordar las posibilidades de reforma de la Cámara alta en su composición (designación de sus miembros por los Gobiernos o Parlamentos autonómicos, elección directa en circunscripción autonómica..) o funciones (redefinición de sus competencias, especialización territorial..), las ventajas o desventajas de cada modelo, el propio orden en que deben ser abordados.. Únicamente nos plantearemos sus relaciones en el supuesto de reforma que aparentemente atenuaría parcialmente la necesidad de actuación de un foro de estas características, esto es, aquel en el que la Cámara alta tuviera, entre otros cometidos, el de ser "foro de cooperación interterritorial". Esa articulación de ese futuro Senado, llevaría, en el plano de su composición, como ha referido Albertí, a concluir que la única composición adecuada para asumir tal misión sería la gubernamental $^{32}$. Ésta sería la fórmula de uno de los modelos habitualmente planteados respecto de nuestro Senado; así, el del Bundesrat alemán, órgano de representación de los Länder a nivel federal ${ }^{33}$ que tendría en el mismo una posición central y determinante, en donde, por lo que a la composición haría referencia, como es de sobra conocido, sus miembros son designados por los gobiernos de los Länder - estando presentes también los Presidentes_-, siendo aquellos, en palabras de Hesse, representantes "instruidos" en contraposición a los diputados, vinculados a prescripciones y órdenes ${ }^{34}$. Partidarios y detractores de ese modelo no faltarían, ello con independencia de reflexiones sobre su propia naturaleza en las que ahora no entraremos ${ }^{35}$. Aja y Viver, por ejemplo, en una reflexión de conjunto sobre la evolución de nuestro Estado autonómico y al abordar este problema señalan que "una reforma del Senado en sentido alemán significaría a la vez un incremento importante de los poderes de las Comunidades Autónomas y una mejora cualitativa del funcionamiento del sistema, ${ }^{36}$. Desde otra perspectiva, Portero nos hablará de un modelo excepcional

32 Señala asimismo este autor que si el Senado mantiene su condición de Cámara parlamentaria difícilmente podría ir más allá de un papel de seguimiento e impulso, cuando menos en las relaciones verticales de colaboración, aunque sí desempeñaría un papel más activo en las relaciones horizontales, Ante el futuro del Senado, cit., págs. 67 y ss. En este mismo volumen véase, también, TRUJILLO, G., «La reforma constitucional y la participación del Senado en las relaciones de colaboración entre el Estado y las Comunidades Autónomas", especialmente las págs. 386 a 391.

33 Sobre este modelo, OETER, S., "La posición del Bundesrat en el sistema constitucional alemán", Teoría y Realidad Constitucional,n. ${ }^{\circ}$ 16, 2005, En prensa.

34 Grundzüge des Verfassungsrechts der Bundesrepublick Deutschland, CF Müller, Heilderberg, 1995, pág. 260.

35 Dispares opiniones sobre la adopción o no de este modelo pueden verse, por citar algunos ejemplos dentro de la amplia bibliografía existente, en PUNSET, R., El Senado y las Comunidades Autónomas, Tecnos, Madrid, 1987; ARBOS, X., «El Senado: Marco constitucional y propuestas de reforma", Revista de las Cortes Generales, n. ${ }^{\circ}$ 24, 1991; PORTERO MOLINA, J. A., "Contribución al debate sobre la reforma del Senado", Revista de Estudios Políticos, n. ${ }^{\circ}$ 87, 1995; MARTÍNEZ SOSPEDRA, M., „El Senado reformado: ¿cámara o consejo?, Cuadernos Constitucionales de la Cátedra Fadrique Furió Ceriol, n. ${ }^{\circ}$ 40, 2002; TORRES DEL MORAL, A., "Veinticinco años de Senado", Revista de Derecho Político, n. ${ }^{\text {os }}$ 58/59, 2003, o AJA, E., El Estado autonómico. Federalismo $y$ bechos diferenciales, Alianza Editorial, Madrid, 2003.

36 "Valoración de 25 años de autonomía", cit., pág. 108. 
en el panorama comparado ${ }^{37}$, mientras que Martínez Sospedra lo considerará una solución inadecuada a los déficits de multilateralidad e integración de nuestra forma de Estado $^{38}$.

En el más que hipotético supuesto de que ese modelo o uno similar se adoptara finalmente, cabría plantearse la necesidad de articular nuevamente la actuación de la Conferencia de Presidentes (sería deseable que en sus diferentes perspectivas), en tanto que teóricamente la cámara alta tendría como una de sus principales funciones el impulso de la colaboración y el fortalecimiento de las relaciones intergubernamentales favoreciendo la cooperación entre las diferentes Comunidades Autónomas, convirtiéndose así en una cámara de integración. Si bien en pura teoría pudiera parecer que a partir de ese momento dicho foro podría llegar a resultar innecesario al convertirse aquel en elemento canalizador (eficaz) de las relaciones entre las Comunidades Autónomas y el Estado, hay una cuestión evidente, y es que la experiencia alemana nos muestra lo contrario: la utilidad de la convivencia de dicho foro y su intercomplementariedad. Allí el Bundesrat y la Conferencia (en sus dos dimensiones) articulan un sistema integrador notable. Esta, por ejemplo, y entre otras actividades "se convierte en una instancia de impulso y preparación de algunos trabajos del Bundesrat, y de muy informal recurso "mediador" en los casos de bloqueo de la decisión en la Cámara parlamentaria "39.

En todo caso, y más allá de que no parezca verosímil que la reforma determine un modelo como el apuntado, parece claro que la Conferencia de Presidentes está llamada a convertirse (repitamos, gestionada de forma inteligente y preteridos, en la medida de lo posible, criterios exclusivamente partidistas) en un adecuado complemento del Senado y elemento importante en nuestro Estado de las Autonomías.

Ello, cualquiera que fuere la reforma que se produzca con relación a nuestro Senado; si es que finalmente termina por producirse, y caso de no verificarse con mucha mayor razón.

En un estudio reciente sobre la Conferencia de Presidentes, construido básica y esencialmente al amparo del modelo alemán tomado como arquetipo, Bocanegra Sierra y Huergo Lora apuntan la compatibilidad y complementariedad de la Conferencia de Presidentes y del Senado; y más aún, de un Senado reformado, al destacar que la territorialización de esta cámara "hace aún más necesaria la Conferencia de Presidentes, al provocar situaciones de bloqueo, derivadas de la existencia de mayorías diferentes en ambas cámaras" a lo que añadirían (al abordar la conveniencia de un foro que reúna al Presidente del Gobierno con los Presidentes de las Comunidades Autónomas) que "esta necesidad de contacto sería mucho mayor si se opta por reformar el Senado para convertirlo en una cámara que represente a las Comunidades Autónomas y en

37 "Contribución al debate sobre la reforma del Senado", cit., pág. 99.

38 " El Senado reformado: ¿̇cámara o consejo?", cit., pág. 88 y ss.

39 En ese sentido, ROIG, E., "La Conferencia de Presidentes de los Länder en Alemania; cfr. AJA, E., Informe sobre la Conferencia de Presidentes, cit., pág. 3. 
especial a los Gobiernos autonómicos ${ }^{40}$. En el mismo sentido Cámara refiere que no cabría hablar en modo alguno de un inevitable y completo solapamiento y conflicto con otros órganos, singularmente con un Senado que efectivamente se reconfigure como Cámara de representación territorial" ello porque «la cualidad de esta función de impulso y orientación política (de la Conferencia de Presidentes) no prejuzgaría ni hurtaría ni el debate político general en el seno de la Cámara, ni el resultado al que eventualmente pudiera llegarse (..) aunque en determinadas materias viniera ya precisada como compromiso político una orientación general sobre la decisión de determinados asuntos y ello pudiera provocar ciertamente tensiones políticas institucionales"; este foro serviría así, entre otras funciones, como "elemento de reequilibrio permanente de carácter general, en tanto la relativa informalidad de esta Conferencia permitiría nuevos tratamientos igualmente informales de aquellos asuntos que pudieran estar políticamente bloqueados en el ámbito parlamentario" $"$.

Esa compatibilidad, esa suerte de intercomplementariedad, incluso necesaria "vinculación", no sería una idea nueva, puesto que casi una década atrás, Fernández Segado, ya señalaba que resultaría positivo en orden al mejor cumplimiento de las funciones del Senado (reformado) el establecimiento de vinculaciones con un órgano, la Conferencia de Presidentes (entonces inexistente) que a su entender debería actuar como instancia deliberante, foro de diálogo y debate del que surgieran las líneas generales de la política autonómica ${ }^{42}$; a ello añadiría de manera específica respecto a los asuntos comunitarios, que el Senado "quizá a través de la vía de la Conferencia de Presidentes" podría "desempeñar un papel destacado en la concertación entre el Gobierno del Estado y los Ejecutivos autonómicos" tanto en "lo concerniente a la defensa de los intereses autonómicos y generales ante los organismos propios de la Unión como en lo relativo a la ejecución del Derecho comunitario" ${ }^{43}$.

No obstante lo anterior lo cierto es que la Conferencia debe desarrollarse, como apuntamos supra, sin plantearse, hasta que exista una realidad concreta, esa reforma del Senado.

Cabe recordar que no mucho tiempo atrás, con inmediata anterioridad a la celebración de la primera de Conferencia de Presidentes autonómicos, expresaba acertadamente esta idea Aja aconsejando no tener en cuenta la variable de la reforma del Senado en la definición de la Conferencia en orden a evitar el

40 La Conferencia de Presidentes, Iustel, Madrid, 2005, págs. 19 y 30, respectivamente.

41 "La Conferencia de Presidentes como instrumento de integración para el Estado autonómico: problemas y perspectivas", cit., pág. 127/128.

42 Entre las otras competencias que apuntaba el autor se encontraba el asupervisar y dirigir la acción de las Conferencias sectoriales y pronunciarse acerca de los proyectos normativos de la UE, pudiendo asimismo coordinar las actuaciones relacionadas con la defensa del Estado ante el TJCE", "Reflexiones en torno a la reforma constitucional del Senado", Revista de Derecho Politico, n. ${ }^{\circ}$ 42, 1996, pág. 51.

43 Íbidem, págs. 51/52. 
condicionamiento de esta por lo que no es sino una incógnita, esa reforma que no llega ${ }^{44}$.

Apostaba el autor por continuar el desarrollo de la Conferencia sin atender a aquella, sobre la base de que su flexibilidad permitiría en su momento, y en su caso, una eventual reconducción a la posición que resultare adecuado, pues "ciertamente la situación futura del Senado podría condicionar de modo intenso la posición y funciones de la Conferenciaw; terminando por señalar, de manera más específica, que "la Conferencia debe plantearse todos los retos abiertos del desarrollo autonómico, sin pensar en su eventual respuesta por el futuro Senado (..) Se trata pues de dos procesos que deben realizarse de forma paralela, procurando la mayor aportación de cada uno al sistema autonómico, pero sin que las actuales incógnitas sobre la reforma del Senado lastren las posibilidades de la Conferencia. La separación de ambas cuestiones es probablemente fundamental para dar una adecuada respuesta a ambas, ${ }^{45}$.

Mientras esa reforma del Senado siga sin ser una realidad (si es que finalmente llega a producirse) parece oportuno seguir abogando por la no formalización jurídica de la Conferencia de Presidentes; tanto de la dimensión vertical que conocemos, como de la dimensión horizontal, en el supuesto - complejo- de que se articule.

Parece cierto que la Conferencia de Presidentes (más allá de exageraciones que han llegado a hablar de ella como punto de arranque de una segunda transición ${ }^{46}$ ) puede alcanzar un lugar de privilegio en nuestro sistema de organización territorial, al menos si se saben aprovechar adecuadamente las oportunidades que abre. Un foro multilateral de encuentro al más alto nivel, contrapunto al bilateralismo al que estábamos acostumbrados, que, claro está, resultaba preferido desde algunos concretos sectores por la posibilidad de obtención de mayores réditos ${ }^{47}$; un bilateralismo insuficiente y empobrecedor, sin duda, del Estado autonómico ${ }^{48}$. La existencia de una generalizada voluntad

44 Informe sobre la Conferencia de Presidentes, cit., pág. 20. Véase, también de este autor, "La reforma constitucional del Senado para convertirlo en una Cámara autonómica", cit. especialmente las págs. 22 a 24, "La Conferencia de Presidentes en el Estado autonómico", Constitución, Estado de las autonomías y justicia constitucional, VVAA, Tirant lo Blanch, Valencia, 2005, págs. 835/836;

45 Desde otra perspectiva, J.M. MORALES apunta que la propia reforma del Senado tenga en cuenta la existencia de esa Conferencia en diferentes cuestiones, así, por ejemplo, con relación a la composición del Senado y a la posibilidad de incluir como miembros natos a los Presidentes de las Comunidades Autónomas, propuesta que él no compartiría, Informe sobre la reforma del Senado, Junta de Andalucía, 2005, pág. 19.

46 GÓMEZ, J. L. A vueltas con España, Temas de hoy, Madrid, 2005, pág. 196.

47 J. J. SOLOZABAL, junto al temor de algunas comunidades nacionalistas de que en foros multilaterales dejen de estar singularizadas, destaca también la eventual actitud ventajista del Gobierno de la Nación temeroso de quedar en minoría en relaciones de este tipo, Nación y Constitución. Soberanía y autonomía en la forma política española, Biblioteca Nueva, Madrid, 2004, págs. 337/338; véase, igualmente, CORCUERA, F.J., "Colaboración y cooperación en el sistema autonómico español". Anuario Jurídico de la Rioja (El Estado autonómico: cooperación y conflicto), n. ${ }^{\circ}$ 8, 2002, esp. págs. 221 y ss.

48 Como señala E. AJA "la inexistencia de instituciones y técnicas eficaces para las relaciones intergubernamentales entre las CCAA y de éstas con el Estado son el punto débil de toda la estructura autonómica", El Estado autonómico. Federalismo y bechos diferenciales, cit., págs. 204 y ss. 
de colaboración unida al hecho de que las directrices partidistas o las coyunturas políticas no se antepongan, por lo que a los Presidentes autonómicos hace referencia, a la representación de sus respectivos territorios — sin olvidar los objetivos que pueda obtener a corto o medio plazo ${ }^{49}$ - será lo que determine que este foro o mecanismo de cooperación pueda convertirse o no en una pieza básica del engranaje de nuestro Estado autonómico ${ }^{50}$.

ABSTRACT. The aim of this paper is to focus the attention in the Committee of Autonomous Communities President's and to try to link this new forum of discussion and negotiation with the problem of the reform of the Senate. Should that Committee fulfil its task properly, it would become an useful instrument of participation for the Autonomous Communities, and could help to temper differences and make the whole system work efficiently.

De deficiencia hablará también R. PINEDA tras señalar que pese a los grandes avances en descentralización política de nuestro modelo autonómico se ha profundizado escasamente en los elementos de cooperación intergubernamental, La participación territorial en la Cámara Alta en Estados federales o descentralizados, INAP-Goberna, Documento de Trabajo n. ${ }^{\circ}$, julio de 2004, págs. 3 y ss.

49 En un trabajo publicado justo con anterioridad a la celebración de la primera Conferencia se apuntaba precisamente esta idea, esto es, que "la importancia que cobre la Conferencia de Presidentes en los próximos años dependerá de los objetivos que logre a corto y medio plazo" así como que «el buen rendimiento de la Conferencia permitirá el establecimiento de una compleja red de relaciones intergubernamentales a largo plazo en todos los niveles de la administración", Conferencia de Presidentes. Modelos y prácticas en derecho comparado,VIDAL, J. M., (Dir.), INAP-Goberna, Documento de Trabajo n. ${ }^{\circ}$ 3, septiembre de 2004, pág. 24.

50 Encontrándose en pruebas este trabajo el Consejo de Estado ha dado a conocer su Informe sobre la reforma constitucional (febrero de 2006) en donde, al hilo de la eventual reforma del Senado, se ha planteado cuestiones atinentes a la propia Conferencia de Presidentes. Por un lado, la posibilidad de la previsión constitucional expresa de que el Senado sea la sede de dicha Conferencia como "elemento de cooperación orgánica y funcional y de encuentro político", cuestión que desecha al "parecer preferible evitar su reconocimiento constitucional por la propia naturaleza de tales reuniones y la necesaria flexibilidad de su régimen" pues su "éxito y eficacia dependen de la voluntad política existente al respecto y de la conciencia de la necesidad de una actuación conjunta más que de su plasmación en el texto constitucional». Por otro, la posibilidad de que con relación a determinados nombramientos (Magistrados del Tribunal Constitucional, por ejemplo) sea la Conferencia de Presidentes la que elabore ternas entre las que hubiera de elegir el Pleno del Senado; sobre este punto señalará que la pretendida insuficiencia de participación de las Comunidades Autónomas quedaría superada con un Senado más acorde con su naturaleza de Cámara de representación territorial, como en el Informe se razona, destacando que el Reglamento del Senado podrá arbitrar el mecanismo que considere más adecuado y transparente en fase de elaboración de las propuestas de candidatos. 